\title{
SCMS.04. Effect of sodium nitrite in a model of depressive-like behavior induced by LPS in mice \\ TOMAZ, V.S. ${ }^{1}$, CORDEIRO, R.C. ${ }^{2}$, MONTEIRO, I.O. ${ }^{3}$, ROCHA, N.F.M. ${ }^{3}$, MACÊDO, D.S ${ }^{3}$. \\ ${ }^{1}$ Departamento de Microbiologia Médica, Faculdade de Medicina, Universidade Federal do Ceará \\ ${ }^{2}$ Departamento de Medicina Clínica, Faculdade de Medicina, Universidade Federal do Ceará \\ ${ }^{3}$ Departamento de Fisiologia e Farmacologia, Faculdade de Medicina, Universidade Federal do Ceará
}

Introduction: Psychiatric disorders, including depression, are among the leading causes of disability worldwide. In this context, research about new pathways involved in the pathophysiology of this mental disorder with the search of new targets for the treatment of this disorder has been widely studied. Studies confirm that the increased levels of nitrite are directly related to depression, based on this hypothesis we consider that the administration of organic nitrites can accentuate the depressive-like behavior in an experimental model. Objectives: To evaluate the effects of Sodium Nitrite in a model of depressive-like behavior induced by LPS in mice. Methods: Adult male Swiss mice (20-30g, $\mathrm{n}=6-8$ per group) were treated with sodium nitrite $(50 \mathrm{mg} / \mathrm{kg}$, ip), imipramine $(10 \mathrm{mg} / \mathrm{kg}$, ip), LPS (0.5 mg / $\mathrm{kg}$, ip) or saline. Animals were divided into four groups, two were pretreated with sodium nitrite or Imipramine 30 minutes before LPS administration, one received only the dose of LPS and the control group received only saline. Animals were submitted to evaluation of the depressive-like behavior through the forced swimming test, $24 \mathrm{~h}$ after LPS administration. After behavioral testing, animals were sacrificed by cervical dislocation and their brain areas: Pre-frontal Cortex (PF), Striatum (ST) and Hippocampus (HP) were separated and stored at $-80^{\circ} \mathrm{C}$ for later measurement of nitrite levels by method according to Gries. The statistical analysis was performed by ANOVA followed by Tukey's test, considering significant $p<0.05$. The project was approved by the Ethics Committee on Animal Research of UFC. Results: When compared to control group, animals that received only LPS increased the immobility time (control: $68.71 \pm 17.05$, LPS: $151.30 \pm 9.58$ ). Pretreatment with imipramine, an antidepressant drug, significantly reduced the immobility time (50.20 \pm 3.00) when compared with the group treated with LPS. The brain levels of nitrite in animals pretreated with sodium nitrite significantly increased when compared to control and LPS groups. It is noteworthy that there was a decrease in the levels of nitrite of animals pretreated with imipramine when compared to LPS and control groups (PF- LPS: $50.90 \pm$ 9.67, Control: $126.40 \pm 71.90$, Imipramine: $26.82 \pm 1.59$; Sodium nitrite: $304.90 \pm 60.81$; HP- LPS: $86.23 \pm 40.84$, Control: $299.70 \pm 73.89$, Imipramine: $26.82 \pm 1.59$; Sodium nitrite: $384.2 \pm 77.39$; ST: LPS: $145.80 \pm 64.93$, Control: $184.1 \pm 19.89$, Imipramine: $26.82 \pm 1.59$; Sodium nitrite: $163.7 \pm 25.40$ ). Conclusions: Sodium nitrite significantly increased immobility time and nitrite levels, suggesting that the increase in the supply of sodium nitrite is capable of increasing the depressive-like effects induced by LPS.

\section{Keywords: Depression, LPS, Sodium Nitrite.}

TOMAZ, V.S.; CORDEIRO, R.C.; MONTEIRO, I.O.; ROCHA, N.F.M.; MACÊDO, D.S. 2013. Effect of sodium nitrite in a model of depressive-like behavior induced by LPS in mice, p.14. In: Oriá, Reinaldo Barreto; Andrade, Geanne Matos de; Bruin, Veralice Meireles S. de.

I International Symposium in Neuroscience Meeting [Blucher Neuroscience Proceedings n.1 v.1]. São Paulo: Blucher, 2014, http://dx.doi.org/10.5151/isnm-sine9 